\title{
IT GOVERNANCE: A STRATEGIC ALIGNMENT FOR INFORMATION TECHNOLOGY/BUSINESS
}

\author{
Henderi $^{1}$ \\ Yeni Nuraeni ${ }^{2}$ \\ Junaidi $^{3}$ \\ Rahmad Hidayat ${ }^{4}$ \\ E-mail: Henderi@pribadiraharja.com,Junaidi@faculty.raharja.ac.id, \\ rahmathidayat@ti.raharja.ac.id \\ yeninur@hotmail.com
}

Diterima :24 Juni 2010/Disetujui : 6 Agustus 2010

\begin{abstract}
ABSTRAK
Information technology (IT) merupakan critical asset untuk menciptakan tata kelola organisasi yang efektif. Karena itu, organisasi dan para ahli IT dan bisnis membutuhkan IT governance yang baik. IT governance berperan sebagai sarana untuk penyelarasan IT dengan bisnis, diperlukan untuk menjelaskan peran baru organisasi IT, mengukur kontribusi masing-masing komponen organisasi, membantu mengetahui dampak dan manfaat investasi IT yang telah dilakukan, pengambilan keputusan, dan mendapatkan proyek yang lebih baik. Sebaliknya, IT governance organisasi yang tidak efektif dapat menyebabkan kerugian bisnis, penurunan reputasi, melemahkan kemampuan daya saing, ketidak tepatan jadwal proyek, pemborosan biaya, mutu produksi tidak sesuai dengan harapan, inefisiensi, serta tidak terpenuhinya inovasi dan keuntungan yang telah dijanjikan. Sementara itu, strategic alignment (pada IT business) yang baik dapat menciptaan peluang baru dan meningkatkan keunggulan kompetitif yang lebih tinggi bagi perusahaan. Dengan demikian strategic alignment diperlukan untuk menciptakan alignment antara IT-business dan menjamin IT governance berjalan sesuai dengan yang telah ditetapkan. Artikel ini bermaksud membahas dan memberikan informasi tentang strategic alignment IT-business sebagai salah satu komponen IT governance yang baik. Setelah memahaminya, para direksi
\end{abstract}

1. Dosen Jurusan Teknik Informatika, STMIK Raharja

Jl. Jend. Sudirman No. 40 Cikokol - Tangerang Telp. 5529692

2. Dosen Program Studi Teknik Informatika Universitas Paramadina - Jakarta

J1. Jend. Gatot Subroto Kav.96-97, Jakarta Selatan 12700, Indonesia

3. Dosen Jurusan Teknik Informatika, STMIK Raharja

Jl. Jend. Sudirman No. 40 Cikokol - Tangerang Telp. 5529692

4. Mahasiswa Jurusan Teknik Informatika, STMIK Raharja Jl. Jend. Sudirman No. 40 Cikokol - Tangerang Telp. 5529692 
dan CEO dapat mengidentifikasi peluang dan menyusun strategic alignment yang baik untuk meningkatkan IT business alignment dalam rangka menjamin kelangsungan perusahaan.

Kata kunci : critical asset, IT governance, strategic alignment IT business

\begin{abstract}
Information technology (IT) is a critical asset for effectiveness organizational governance. Therefore, the organization's and IT's and business's expertise need a good IT governance. IT governance as a tool for aligning IT with business, is required to explain the new role of IT organizations, measuring the contribution of each organization's components, helping identify the impact and benefits of IT investment which has been done, decision making, and make a better project. Conversely, the IT governance which ineffective can lead to losses of business, impairment of reputation, weaken the ability of competitiveness, lack of precision project, inefficient, quality of production is not in line with expectations, and inability to fulfill the innovation and benefits that were promised. Meanwhile, strategic alignment (in the IT business) which can either creating new opportunities and increased competitive advantage for companies well. Thus, it is necessary to create strategic alignment IT-business and ensure IT governance goes according to planned. This article intends to discusse and provide information about strategic IT-business alignment as one component of good IT governance. Once understood, the directors and CEO can identify opportunities and develop a good strategic alignment to increase IT business alignment in order to ensure companies continuity.
\end{abstract}

Key words: critical assets, IT governance, strategic alignment of IT business

\title{
PENDAHULUAN
}

Penanganan IT pada organisasi selalu menjadi masalah bagi para top eksekutif karena sifat teknis dari IT. Keputusan-keputusan kunci tentang IT hanya diserahkan kepada profesional TI. Sementara tata kelola IT (IT governance) menyiratkan suatu sistem di mana semua stakeholder, termasuk dewan direksi, pelanggan internal, dan bidang terkait seperti keuangan dan sumber daya manusia diperlukan masukannya dalam proses perencanaan dan pengambilan keputusan tentang IT agar tercipta IT business alignment dalam organisasi. Perencanaan yang baik merupakan fokus utama penerapan IT business alignment pada IT governance. IT business alignment harus sejalan dan sesuai dengan harapan organisasi dan dibutuhkan untuk mendukung pencapaian visi dan misi yang telah ditetapkan. IT business aligment mengarah dan menyoroti peran IT dalam pengembangan strategi bisnis dengan mempertimbangkan penyelarasan sumber daya 
infrastruktur dan pengintegrasian fungsional IT dan bisnis. Untuk itu diperlukan strategic alignment dan langkah-langkah serius dalam menerapkannya untuk mendukung dan menunjang kelangsungan organisasi.

Pencapaian strategic alignment internal terjadi ketika pengarah dari network konsisten dan sejajar dengan keinginan pelanggan dan pendapatan. Namun demikian, penerapan IT pada organisasi masih banyak yang belum efektif, dilakukan secara tradisional, belum alignment dengan bisnis, dan pengambilan keputusan kunci dibidang IT dilakukan dan diberikan hanya kepada para profesional IT saja. Hal ini disebabkan karena para direksi mempunyai keterbatasan pengetahuan dan pengalaman teknik dibidang IT. Sementara IT governance organisasi yang tidak efektif dapat menyebabkan [1]: kerugian bisnis, penurunan reputasi, melemahkan kemampuan daya saing, ketidak tepatan jadwal proyek, pemborosan biaya, mutu produksi yang tidak sesuai dengan harapan, mempengaruhi efisiensi organisasi, serta tidak terpenuhinya inovasi dan keuntungan yang dijanjikan. Pada bagian lain, Tiwana et al. [2] menemukan bahwa integrasi pengetahuan berpengaruh secara positif terhadap fleksibilitas dalam proyek TI organisasi. Karena itu, pengetahuan tentang strategic alignment IT business para direksi, eksekutif dan stakeholder organisasi yang menerapkan IT perlu dikembangkan. Artikel ini bermaksud membahas dan memberikan informasi tentang strategic alignment IT - business sebagai salah satu komponen IT governance organisasi.

\section{PEMBAHASAN}

\section{Fokus IT Governance}

IT Governance mencakup pembuatan keputusan, akuntabilitas pelaksanaan kegiatan penggunaan IT, siapa pengambil keputusan, mengolah proses pembuatan keputusan, dan pengimplementasian keputusan-keputusan yang berkaitan dengan IT dalam organisasi.IT Governance menyediakan struktur, menghubungkan proses IT, sumber daya IT, dan informasi bagi strategi serta tujuan suatu organisasi. Karenanya, IT governance menjadi enabler bagi organisasi dalam memperoleh keuntungan yang maksimal dari informasi yang dimiliki dengan memaksimalkan peluang dan keuntungan kompetitif organisasi. Untuk dapat memiliki IT governance yang efektif, organisasi harus mengimplmentasikan IT governance focus area [3] secara holistik. 
Tabel 1. IT Governance Focus Area [3]

\begin{tabular}{|c|c|c|}
\hline No. & Fohus Area /Bidang & Keterangan \\
\hline 1. & Strategic Aligrment & 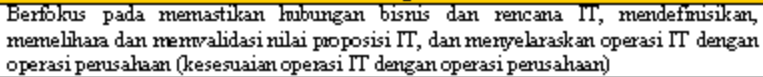 \\
\hline 2. & Vahe Delivery & 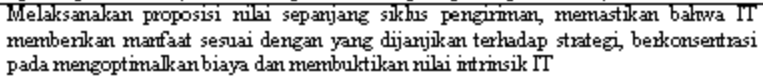 \\
\hline 3. & Resource Management & 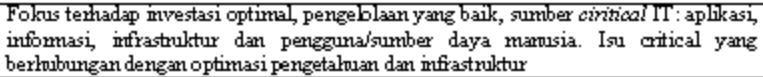 \\
\hline 4. & Fisk Maragement & 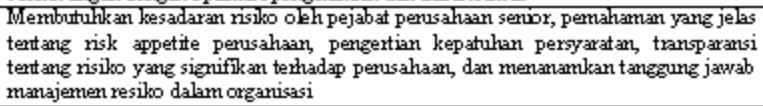 \\
\hline 5. & Perfomace measuement & 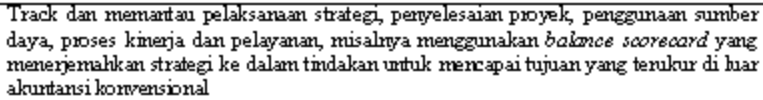 \\
\hline
\end{tabular}

Tampak pada tabel 1, strategic alignment merupakan unsur pertama dalam IT governance yang berfokus dalam memastikan hubungan bisnis dan perencanaan IT, mendefinisikan, memelihara dan mengukur validasi nilai proporsi IT, dan menyelaraskan (alignment) operasi IT dengan operasi perusahaan. Strategic alignment merupakan fokus utama, berperan strategis, dan dominan dalam memenuhi harapan penerapan IT terhadap pencapaian visi, misi dan keberlangsungan suatu organisasi. Namun demikian, IT governance biasanya bekerja secara berbeda antara praktek dengan teorinya. Bekerja atau tidaknya IT governance sebagian besar karena hubungan antara manusia, bukan karena struktur atau proses. Oleh karena itu, Reich dan Benbasat [4] menjelaskan bahwa selain memiliki pengetahuan bisnis, para eksekutif hendaknya juga memiliki kemampuan IT dan saling memahami perspektif lain, berkontribusi untuk proses input masing-masing, dan menghormati kontribusi dan tantangan yang dibuat oleh satu sama lainnya.

\section{Alignment within IT-Business}

IT bisnis alignment telah diidentifikasi sebagai sumber daya organisasi yang penting, memfasilitasi fleksibilitas IT dan fleksibilitas bisnis [5]. Karena itu strategic alignment of IT business menekankan otoritas pada IT governance yang baik, dan memastikan IT memberikan kontribusi secara efektif terhadap pencapaian tujuan strategis organisasi [6]. Organisasi harus membangun keselarasan dalam proses IT governance, disusun dengan baik, menjadi tujuan kelembagaan, dan dapat diartikulasikan. Tujuannya adalah menyediakan kerangka tujuan strategi IT, melakukan pengukuran dan penilaian tahunan, dan menguji keselarasannya. Perencanaan strategis IT dan strategic alignment yang efektif dapat dicapai jika IT governance organisasi dilaksanakan, dikembangkan/dibangun secara modern dengan memperhatikan aspek eksternal, melibatkan pihak eksternal, para 
stakeholder, direksi, komisaris, dan pihak yang tidak berlatar belakang IT. Tetapi Chan et al. [7] menjelaskan bahwa rekan IT yang kompeten lebih mungkin untuk dipercaya dan berkonsultasi dalam proses pengambilan keputusan, sehingga mereka lebih sadar akan perkembangan bisnis baru dan mengoperasikannya dalam persyaratan bisnis yang muncul. Dengan demikian strategic alignment dapat disusun secara komprehensif, mencakup seluruh proses bisnis, alignment dengan semua komponen dalam organisasi. Strategic aligment tidak boleh diarahkan kepada satu capaian tertentu, tetapi dipengaruhi dan ditengahi oleh faktor yang lain, seperti kelurusan antara strategy IT dan business strategy [8].

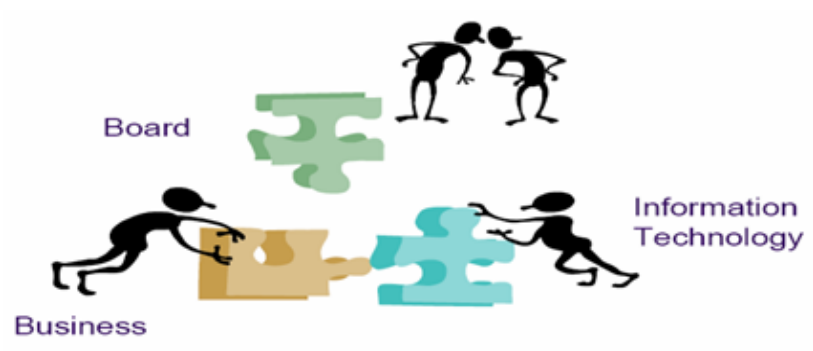

Gambar 1. Kondisi dan usaha strategic aligment of IT governance

Gambar 1 mengilustrasikan kondisi IT organisasi yang tidak memiliki IT governance dan strategic alignment yang baik. IT governance organisasi yang tidak baik/ tidak efektif dapat menyebabkan: kerugian bisnis, penurunan reputasi, melemahkan kemampuan daya saing, ketidak tepatan jadwal proyek, pemborosan biaya, mutu produksi yang tidak sesuai dengan harapan, mempengaruhi efisiensi organisasi, serta tidak terpenuhinya inovasi dan keuntungan yang dijanjikan [1].

Strategic alignment IT business yang baik dimulai dari sistem perencanaan dan pengendalian [9], dan mengacu pada konsistensi aktivitas internal dalam menerapkan dan membedakan komponen strategi IT business aligment. Strategic alignment IT business bertujuan untuk mengatasi jurang kesenjangan yang besar antara tujuan organisasi dan pemahaman penyedia/ pengelola layanan TI [10]. Strategic alignment IT business juga dapat berperan dalam hal penetapan strategis yang tepat, penyelarasan, dan keselarasan organsasi dan sumber daya manusia [12]. Peran strategic aligment ini ditegaskan oleh McKinsey [11] yang menyatakan bahwa investor membayar premi yang besar untuk investasi di perusahaan-perusahaan dengan standar tata kelola yang tinggi. 


\section{Strategic Alignment for IT-Business}

Alignment ditafsirkan sebagai keterkaitan yang direncanakan dan koheren terus-menerus antara semua komponen perusahaan, personalia, dan sistem IT sehingga memberikan kontribusi terhadap performance perusahaan [12]. Strategic alignment diinterpretasikan sebagai proses yang berkesinambungan dari keterkaitan sadar dan koheren dari semua komponen dan personil bisnis dan TI dalam rangka memberikan kontribusi terhadap kinerja organisasi dari waktu ke waktu [12]. Strategic alignment berfokus pada kegiatan manajemen untuk meningkatkan performance kohesif dibidang IT dan bagian fungsional organisasi lainnya, misalnya: keuangan, pemasaran, sumber daya manusia, dan manufaktur [13]. Sehubungan dengan hal ini, Tallon dan Kraemer [14] telah menemukan bahwa alignment tertinggi terdapat pada produksi,operasi, dan hubungan pelanggan, dan yang terendah terdapat pada dalam penjualan dan pemasaran. Pendapat yang lainnya menyatakan bahwa rancangan dan strategic alignment IT business adalah domain dari enterprise architecture [15]. Para peneliti telah menunjukkan bahwa keselarasan strategis berkorelasi dengan kinerja perusahaan [16].

Sementara Marquest P et al. [17] dan Ekstedt et al. [18] menyatakan bahwa empat perspektif IT business aligment strategic yang berbeda berhubungan satu sama lain (lintas domain) ketika kesesuaikan strategis dan integrasi fungsional dalam model SAM dinilai secara bersamaan. Keempat perspektif strategis tersebut adalah: (a) perspektif strategi eksekusi,(b) perspektif potensi teknologi,(c) perspektif potensi kompetitif, dan (d) perspektif tingkat pelayanan [19]. Perspektif ini diklasifikasikan dalam dua kategori yang meliputi: (i) strategi bisnis sebagai driver yang mencakup perspektif pelaksanaan strategi dan teknologi perspektif potensial, dan (ii) strategi IT sebagai enabler yang mencakup perspektif potensial kompetitif dan tingkat pelayanan perspektif.

IT business strategic alignment memiliki fokus dalam memastikan hubungan antara bisnis dan rencana TI, menentukan, merawat dan memastikan IT value proposition; dan pada aligning IT operation [9]. Pendapat tentang strategic alignment ini diperkenalkan oleh Henderson dan Venkatraman [18] yang dijadikan landasan filosofi berfikir seperti pada gambar 2 . 


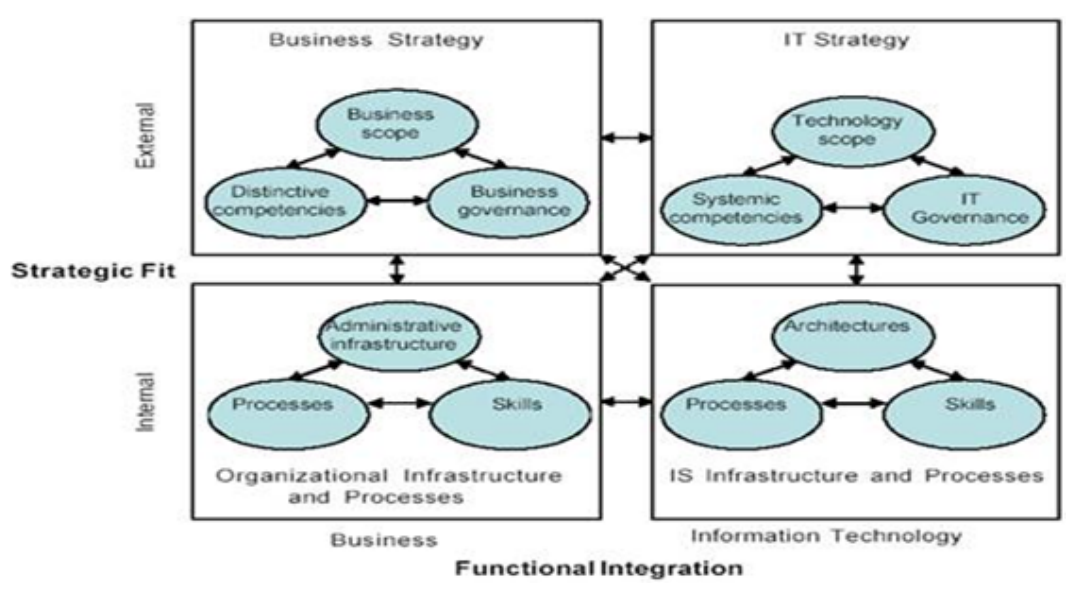

Gambar 2. Strategic fit dan functional integration

Tampak pada gambar 2, strategic alignment dibagi menjadi empat elemen: (a) business strategy, (b) IT strategy, (c) organizational infrastructure and process, (d) IS infrastructure and process. Elemen tersebut terdiri dari dua bagian, yaitu: bagian eksternal (business strategy dan IT strategy), dan bagian internal (organizational infrastructure and process, dan IS infrastructure and process). Keduanya harus diselaraskan dengan menggunakan: (a) strategic fit: bagaimana strategi IT harus dibahasakan dalam domain external (how the firm is positioned in the IT marketplace) dan domain internal (how IT infrastructure should be configered), dan (b) functional integration: bagaimana arah TI akan mempengaruhi arah bisnis (business domain).

Berdasarkan model yang dikenalkan oleh Henderson et al., selanjutnya Marques et al. [17] dan Ekstedt et al. [18] membuat strategic aligment model dan menetapkan empat bagian yang harus bersinergi untuk mencapai alignment: (i) business strategy, (ii) IT strategy, (iii) organizational infrastructure, dan (iv) theier interdependencies. Berdasarkan beberapa pendapat dan hasil penelitian tersebut, dapat disimpulkan bahwa IT business strategic alignment yang tepat, kredibilitas dan relevan dibangun dengan memperhatikan prioritas IT, anggaran, isuisu bisnis yang paling hangat dan menjadi perhatian organisasi dan pelanggan. Hal ini dapat diperoleh melalui diskusi dengan dengan stakeholder dan pelanggan bisnis untuk memahami apa yang penting baginya. Kebutuhan stakeholder tersebut selanjutnya diterjemahkan kedalam IT business strategic alignment yang mudah 
dipahami oleh para CEO dan pelanggan untuk memastikan bahwa IT dapat memberikan perannya secara optimal untuk memenuhi dan menjawab kebutuhan tersebut.

\section{Strategic Alignment Model and Assessing}

Salah satu contoh model alignment yang baik dikembangkan oleh Luftman [20].Penilaian keselarasan strategis Luftman's menyajikan sebuah pendekatan untuk menentukan alignment bisnis perusahaan-IT berdasarkan enam variabel, yaitu: (i) keterampilan, (ii) teknologi ruang lingkup, (iii) kemitraan, (iv) tata kelola, (v) pengukuran kompetensi nilai, dan (iv) komunikasi [20]. Model tambahan adalah model yang diajukan oleh Laagland et al. [21]. Model ini menetapkan bahwa arsitektur bisnis dan arsitektur IT harus terintegrasi untuk mendapatkan hasil yang total efektif dalam organisasi. Pada bagian lain Henderson dan Venkatraman [19] dalam teorinya mengatakan ada empat model alignment IT business tersebut dapat dicapai (gambar 3).

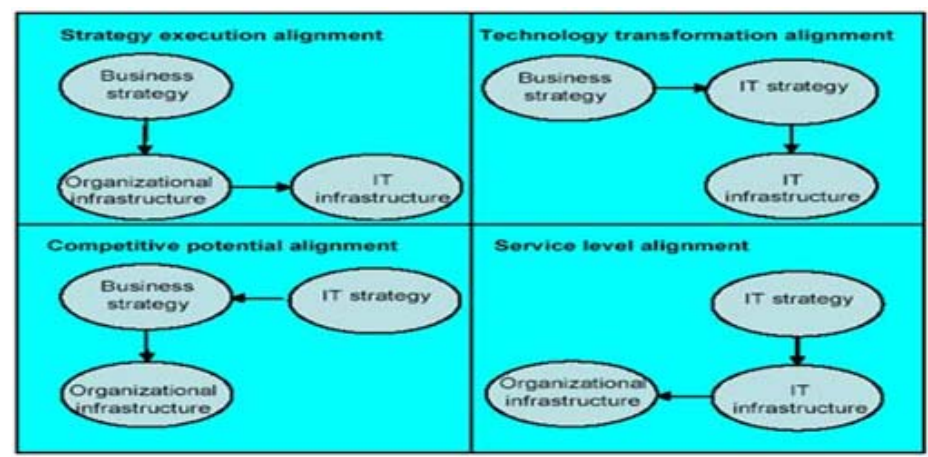

Gambar 3. Model alignment IT business

Berdasarkan gambar 3, model alignment IT business dapat dicapai dengan cara [19]:

\section{1. $\quad$ Strategic execution alignment}

Bersifat hirarkis dan paling umum, dimana strategi bisnis menentukan desain organisasi dan juga desain infrastruktur IT. Strategi ini merupakan yang paling banyak manfaatnya dalam penerapan strategic alignment

2. Technoloy transparmation alignment 
Dimulai dari strategi bisnis, tetapi fokus pada implementasi strategi IT yang tepat, kemudian pada infrastruktur dan proses. Strategi ini memfokuskan pada penerapan strategic agar hasil yang dicapai bisa maksimal.

\section{Competitive potential alignment}

Paradigma ini memungkinkan adaptasi atau munculnya suatu strategi bisnis karena munculnya kapabilitas baru dari IT yang dapat mempengaruhi strategic alignment

\section{4. $\quad$ Service level prespektive}

Cara pandang ini lebih berpikir pada bagaimana cara membuat unit/organisasi IT yang menyediakan layanan prima. Sehingga proses ini berjalan dengan baik pula sesuai dengan kebutuhan dan jenis oraganisasi yang di bentuk.

Terciptanya strategic alignment yang baik melalui penerapan salah satu model alignment tersebut di atas dapat meningkatkan peran IT dalam menciptakan peluang dan keunggulan kompetitif perusahaan. Hal ini diperkuat oleh kurva Chappell David [22] seperti pada gambar 4, yang menggambarkan perbedaan peran strategic IT (bagian dari strategic alignment) dan utility IT dalam mendukung dan menciptakan peluang baru dan meningkatkan kemampuan kompetitif.

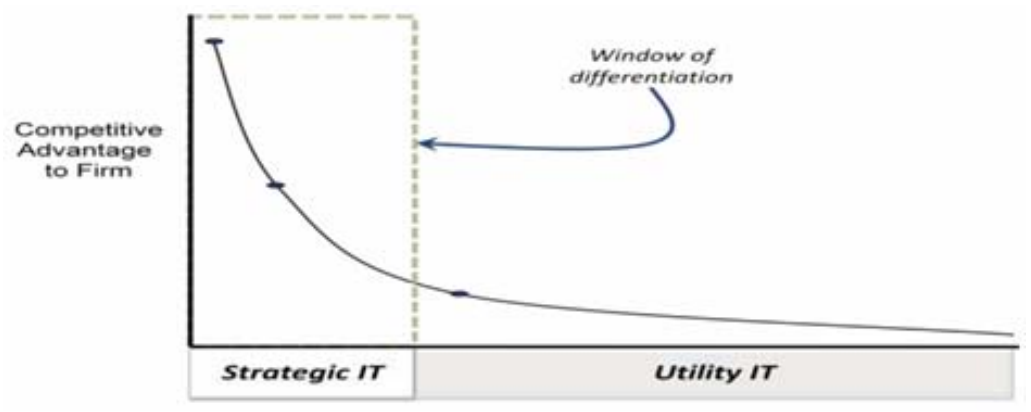

Gambar 4. Kurva peran strategic IT dan utility IT dalam menciptakan peluang dan keunggulan kompetitif

Berdasarkan gambar 4, tampak bahwa strategic IT dapat mendukung penciptaan peluang baru dan meningkatkan keunggulan kompetitif lebih tinggi bagi perusahaan dibandingkan dengan utility IT tanpa strategic. Dengan demikian dapat disimpulkan bahwa strategic alignment IT business sangat dibutuhkan oleh organisasi untuk mengoptimalkan peran IT dalam mencapai tujuan organisasi, menciptakan peluang dan meningkatkan kemampuan kompetitif. 
Sementara itu, strategic aligment yang sudah ditetapkan dapat berjalan sesuai dengan yang telah ditentukan diperlukan assessment (pemantauan) secara tertatur yang ditetapkan dalam bentuk assessing strategic alignment. Terdapat beberapa teori yang berkaitan dengan pengaruh pencapaian bisnis dan kelelarasan IT-bisnis. Hasil penelitian Smit Martin et al. [23], telah meringkas teori utama dan mengembangkannya menjadi model riset untuk menilai hubungan antara penguasaan IT (pengambilan keputusan tentang IT), alignment antara kebutuhan business dan jasa sistem informasi/IT, kualitas informasi, dan kinerja business process pada suatu organisasi. Model assessing strategic alignment dibuat untuk menggambarkan efektivitas IT dan pencapaian bisnis [24].

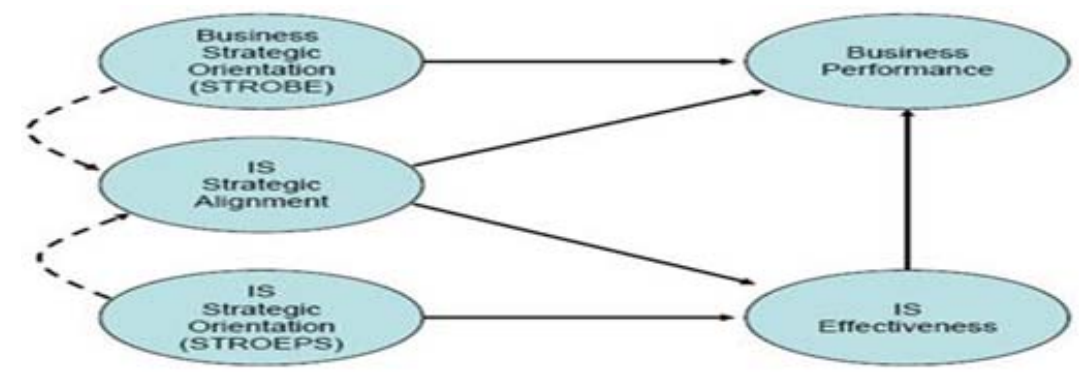

Gambar 5. Kerangka keselarasan efektivitas strategi sistem

informasi terhadap capaian bisnis

Tampak pada gambar 5, strategic alignment digambarkan sebagai keselarasan antara orientasi bisnis unit yang strategis, orientasi sistem yang strategis, dan mengkalkulasi tigkat kelurusan strategis sistem yang digunakan perusahaan untuk mendukung orientasi strategis. Sehubungan dengan hal ini, Chan et al. [24] dan Melville et al. [8] telah melakukan pengujian dampak strategic alignment. Hasilnya menyatakan bahwa dampak strategic aligment tidak boleh diarahkan kepada satu capaian tertentu, tetapi dipengaruhi dan ditengahi oleh faktor yang lain, seperti kelurusan antara strategy IT dan business strategy [8].

Model Chan et al. [24] menilai capaian bisnis dan alignment sistem informasi yang strategis dengan menggunakan lima keselarasan yaitu: (i) orientsi strategis dari business enterprise, yaitu realized business strategy, (ii) performance bisnis, (iii) efektivitas IT atau sistem informasi, yaitu kontribusi IT terhadap bisnis dan nilai saat ini yang ditaksir dengan menentukan kepuasan bisnis, sistem informasi, pengelolaan, jasa, informasi produk, termasuk pengembangan kompetensi end user, 
(iv) orientasi strategis dari portopolio saat ini dari aplikasi sistem informasi, yaitu strategi sistem informasi yang direalisir, yang diperkirakan dengan menentukan sistem informasi yang mendukung bisnis internal, dan (v) strategic alignment sistem informasi, yaitu menghitung skor business strategic orientation dan information systems/IT strategic orientation.

\section{KESIMPULAN}

Strategic alignment adalah bagian pertama dari lima aspek pada IT governance, dan berpengaruh terhadap pencapaian hasil investasi IT. Strategic alignment IT business dalam kegiatan organisasi sangat penting karena konsep strategic bisa memperhitungkan segala sesuatu yang akan dihadapi oleh tata kelola organisasi. Strategic alignment memiliki fokus dalam memastikan hubungan antara bisnis dan rencana IT, menentukan, merawat, dan memastikan pengunaan IT dapat mendukung pencapaian tujuan dan menjamin kelangsungan organisasi. Strategic alignment yang baik, tepat, kredibilitas dan relevan dibangun dengan memperhatikan prioritas IT, anggaran, isu-isu bisnis yang paling hangat dan menjadi perhatian organisasi dan pelanggan, melibatkan para direksi, CEO, semua bagian di organisasi, dan pelanggan bisnis untuk memahami apa yang penting. Kebutuhan stakeholder tersebut selanjutnya diterjemahkan kedalam IT business strategic alignment yang mudah dipahami oleh para CEO dan pelanggan untuk memastikan bahwa IT dapat memberikan perannya secara optimal dalam memenuhi dan menjawab kebutuhan tersebut. Strategic alignment yang disusun secara baik dapat menciptaan peluang baru dan meningkatkan keunggulan kompetitif yang lebih tinggi bagi perusahaan.

\section{DAFTAR PUSTAKA}

[1] Martin Palmgren (2010). Priorities from an Executive Management Perspective. Effective IT Performance Management, IT Governance, Ltd, Linkedin Group.

[2] Tiwana,A., Bharadwaj,A. and Sambamurthy, V.(2003). The Antecedents of Information Systems Development Capability in Firms: A knowledge Integration Perspective, Proceedings of the 24th International Conference in Information Systems, 246-258.

[3] Kris Seeburn, (2008). COBIT as an IT Governance Mechanism, IT Governance Institute and ISACA 
[4] Reich, B.H., and Benbasat, I. (2000). Factors that influence the social dimensions of alignment between business and information technology objectives. Management Information Systems Quarterly, 24 (1), 81-113.

[5] Wagner,H.-T.(2007).AResource-based Perspective on IT Business Alignment and Firm Performance: Theoretical foundation and empirical evidence, ibidem Verlag, Stuttgart.

[6] Jean-Pierre Garbani, Simon Yates and Rachel Batiancila. (2007). The Key To IT Business Alignment Is In Operations, Forrester Research, Inc.

[7] Chan, Y., Sabherwal, R., and Thatcher, J.(2006). Antecedents and outcomes of strategic IS alignment: an empirical investigation. IEEE Transactions on Engineering Management, 53 (1), $27-47$.

[8] Melville, N., Kraemer, K. L. and Gurbaxani, V. (2004). Review: Information Technology and Organizational Performance: An Integrative Model of IT Business Value, MIS Quarterly, 28, 2, 283-322.

[9] Moeller L.,Egol M. and Martin K. (2004). Smart customization: Profitable growth through tailored business streams, Strategy+Business. BoozAllen Hamilton p. 1-2

[10] Ward, J.,Peppard, J. 2002. Strategic Planning of Information System. Third Edition, John Wiley \& Son

[11] Weill, Peter and Jeanne W. Ross. (2004). IT Governance. How Top Performers Manage IT Decision Rights for Superior Results (Boston: Harvard Business School Press.

[12] Maes, R., Rijsenbrij, D., Truijens, O., Goedvolk, H. (2000). Redefining Business - IT alignment Through a Unified Framework. white paper, http:// imwww.fee.uva.nl/ maestro/PDF/2000-19.pdf

[13] Jerry Luftman (2000) . Asseing Business-IT Alignment Maturity. School of Management Stevens Institute of Technology, Communications of AIS, Volume 4, Article 14

[14] Tallon, P., and Kramer,K. (2003). Investigating the Relationship between Strategic Alignment and Business Value: The Discovery of a Paradox. Creating Business Value with Information Technology: Challenges and Solutions. Idea Publishing Group, N. Shin (editor). 
[15] Duffy, J. (2007) IT/Business Alignment: Delivering Results, CIO Magazine, 2001, re-trieved from http://www.cio.com/analyst/123101 idc.html on September 2004

[16] Sabherwal, R., and Chan, Y. (2001). Alignment between Business and IS Strategies: a study of prospectors, analyzers, and defenders. Information Systems Research, 12 (1), 11-33.

[17] Marques Pereira Carla and Sousa Pedro.(2003). Getting into the misalignment between Business and information Systems. The 10th European Conference on Information Technology Evaluation, Madrid, Spain

[18] Ekstedt, M., Jonsson, N., Plazaola, L., Silva, E., and Vargas, N. (2005). An Organizational - Wide Approach for Assessing Strategic Business and IT Alignment.PICMET

[19] Henderson, J.C., Venkatraman, N. (1993). Strategic alignment: Leveraging information technology for transforming organizations, IBM Systems Journal, Vol 32, NO. 1.

[20] Luftman, J. 2003. Assessing IT-Business Alignment. Information Systems Management, Vol. 20, Issue 4, pp. 9-15.

[21] Laagland, P., H. van der Zee and Bas Hafkenscheid. (2000). Architectuur als managementinstrument: Multi Client Study. Ten Hagen Stam. In Dutch.

[22] David Chappell. (2008). Applicatioan Lifecycle Management and Business Strategy. David Chappeel \& Associate, Sponsored by Microsoft Corporation, USA

[23] Martin Smits1,Alea Fairchild1, Piet Ribbers1, Koen Milis2, andErik van Geel3. (2009). dari: http://www.itgovernance.com/00/index.php diakses pada tanggal 4 April 2010.

[24] Chan, Y.E.; Huff, Sid L.; Barclay, Donald W.; Copeland, Duncan G. (1997). Business Strategic Orientation, Information Systems Strategic Orientation, and Strategic Alignment. Information Systems Research, Vol.8, No.2, June 1997, pp. 125-150. 